\title{
Enfermedad celíaca y su patogenia
}

\author{
María José Herrera1 ${ }^{1}$, Marcela A Hermosola, \\ Rodrigo Q uera ${ }^{2,3}$.
}

\section{An update on the pathogenesis of celiac disease}

Celiac disease (CD), with a $1 \%$ world-wide prevalence, is an enteropathy caused by an autoimmune reaction to gluten in genetically susceptible individuals, that codify for histocompatibility molecules HLA DQ-2/DQ-8. From the anatomical point of view, CD is characterized by intestinal villous atrophy, crypt hyperplasia, intraepithelial lymphocytosis (IELs) and leukocyte infiltration of the lamina propria. Patients achieve a complete clinical and endoscopic remission with a gluten free diet. However, symptoms and anatomical alterations recur when this protein is reintroduced in the diet. The pathogenic mechanisms in this disease are not yet well understood, but it is clear that genetic, environmental and immunological factors play a role. The latter are the focus of this review, since this is the only autoimmune disease whose precipitating factor for immunological tissue damage is known (Rev Méd Chile 2009; 137: 1617-26).

(Key words: Celiac disease, Gliadin; HLA-D antigens)

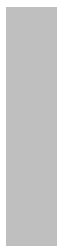

\begin{abstract}
Recibido el 1 de septiembre, 2008. Aprobado el 29 de enero, 2009.
Trabajo parcialmente financiado por Proyecto Fondecyt \# 1070954.

${ }^{1}$ Programa Disciplinario de Inmunología, Instituto de Ciencias Biomédicas, Facultad de Medicina, Universidad de Chile, Santiago de Chile. ${ }^{2}$ Sección de Gastroenterología, Hospital Clínico Universidad de Chile. Santiago de Chile. ${ }^{3}$ Departamento de Gastroenterología, Clínica Las Condes, Santiago de Chile.

aBioquímico, PhD.
\end{abstract}

L a enfermedad celíaca (EC) es una enteropatía provocada por una reacción autoinmune a proteínas del gluten (gliadinas y gluteninas), hordeínas y secalinas, en individuos genéticamente susceptibles ${ }^{1}$. Estas proteínas de reserva ricas en glutamina, son necesarias para la germinación de los granos del trigo, centeno y cebada ${ }^{2}$.

La EC es una patología de distribución global, que puede ser diagnosticada a cualquier edad y que afecta múltiples órganos y sistemas. Tiene

\footnotetext{
Correspondencia a: Dr. Rodrigo Quera. Lo Fontecilla 441, Departamento de Gastroenterología, Clínica Las Condes. Santiago Chile. Teléfono (56-2) 610 8755, Fax (56-2) 6108719. E mail: rquera@clinicalascondes.cl
}

una prevalencia mundial de alrededor de $1 \%$, sin embargo se estima que ésta es aún mayor, ya que $10 \%$ de las personas afectadas son diagnosticadas $^{3}$. En estudios de pesquisa realizados en población sana, en Europa y Estados Unidos de Norteamérica la frecuencia de EC ha sido descrita en 1:100 y 1:150, respectivamente ${ }^{4}$. En Sudamérica estudios han señalado frecuencias de 1:1675 a 1:6816. En nuestro país no existen datos al respecto, pero es claro que su incidencia va en aumento, al igual que en el resto del mundo ${ }^{7}$. La $\mathrm{EC}$, además, afecta principalmente a jóvenes, en especial mujeres con una proporción de 2,5:14.

La EC se clasifica en clásica y no clásica, de acuerdo a su presentación clínica ${ }^{8}$, incluyendo dentro de la no clásica la forma silenciosa y 
latente. La forma clásica se caracteriza por la presencia de manifestaciones clínicas e histológicas; la silente por la presencia de lesiones histológicas en ausencia de manifestaciones clínicas, y la forma latente por la presencia de anticuerpos positivos, en ausencia de lesiones intestinales y manifestaciones clínicas. La mayoría de los pacientes presenta la forma silente, siendo esta la causa principal del subdiagnóstico de la enfermedad ${ }^{9}$. En nuestro país, se observó que posterior a la infancia, la EC es principalmente oligosintomática y generalmente pasa desapercibida. El 13,8\% de 62 pacientes y $4,8 \%$ de 126 de sus familiares tuvieron una presentación no clásica de la $\mathrm{EC}^{10}$.

Clínicamente esta enfermedad presenta una gran variedad de síntomas, tanto gastrointestinales como extraintestinales, siendo incluso asintomática (Tabla 1). La diversidad de las manifestaciones clínicas se explica por la deficiencia nutricional secundaria a la malabsorción, producto del daño de las vellosidades del epitelio intestinal. Esta deficiencia se reflejaría en un compromiso de múltiples tejidos. El compromiso sistémico de la EC es ejemplificado por su asociación con la dermatitis herpetiforme, una enfermedad crónica, que genera lesiones de la piel asociado con la sensibilidad al gluten. Este daño podría ser provocado por el depósito de anticuerpos antitransglutaminasa epidermal de tipo IgA (eTG-IgA) en la piel $^{11}$. Varias enfermedades autoinmunes han sido asociadas con la EC, sembrando la duda de si esta asociación se relaciona con una predisposición genética o si una respuesta inmune anormal de la mucosa intestinal a los antígenos del lumen, es central en el desarrollo de una enfermedad autoinmune sistémica ${ }^{9}$.

Aunque en la mayoría de los pacientes la dieta es el único tratamiento, la adherencia a ésta es baja dado la dificultad de mantenerla en el tiempo. Los síntomas remiten absolutamente con una dieta sin gluten y reaparecen al reintroducirlo. La ausencia de tratamiento o diagnóstico oportuno se asocia con múltiples complicaciones, tales como mayor riesgo de anemia, infertilidad, osteoporosis y linfoma intestinal. Además, la falta de

Tabla 1. M anifestaciones clínicas en pacientes con EC 4,59

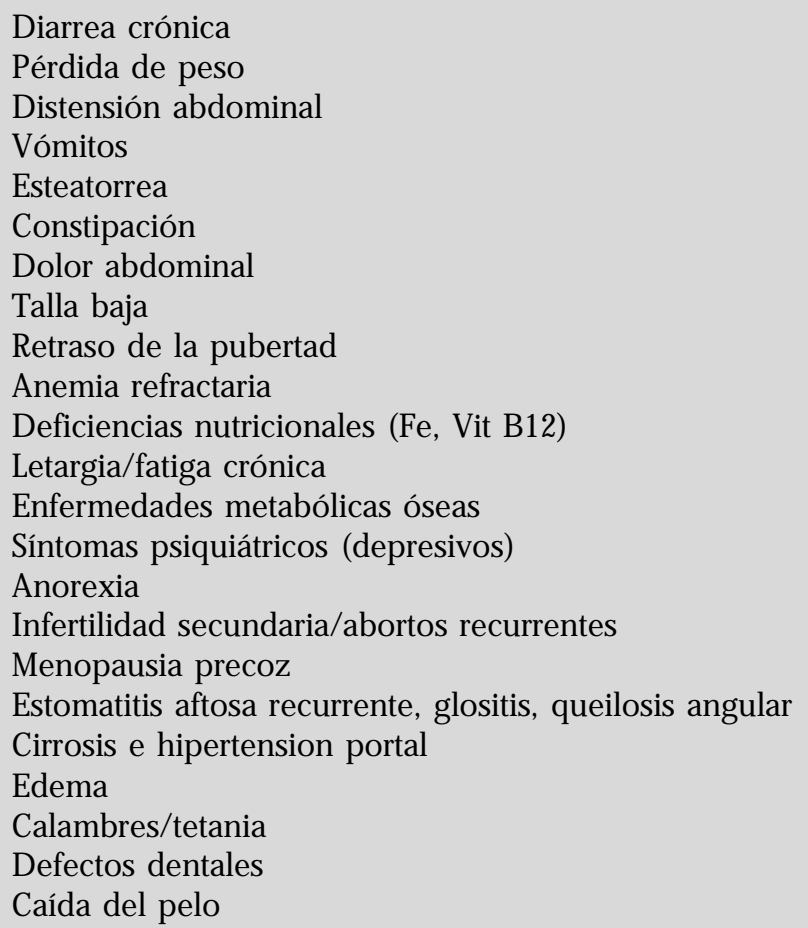


tratamiento está asociada con una mayor mortalidad $^{12}$. Desde el punto de vista anatomopatológico, la EC se caracteriza por la infiltración de linfocitos intraepiteliales y la remodelación tisular ${ }^{13}$. Estos procesos condicionan una hiperplasia de las criptas y atrofia de las vellosidades intestinales, causada por la destrucción de los enteroci$\operatorname{tos}^{14}$, y la infiltración leucocitaria en la lámina propia. El diagnóstico debe plantearse ante la sospecha clínica, y ser confirmado a través de anticuerpos antiendomisio o antitransglutaminasa en el plasma y una biopsia de intestino concordante ${ }^{15}$.

Paralelamente, la prevalencia de déficit de IgA en pacientes con EC es mayor en comparación con individuos sanos ${ }^{16}$. Debido a que un déficit de esta inmunoglobulina puede determinar falsos negativos en la medición de anticuerpos antitransglutaminasa intersticial (tTG) de tipo IgA, es recomendable medir los títulos de IgA totales. En caso de existir déficit de IgA, los niveles de tTG-IgG estarán elevados en la mayoría de los pacientes ${ }^{9}$.

\section{Patogenia}

En la patogenia de EC participan varios factores genéticos, ambientales e inmunológicos, los que hasta ahora no han sido completamente caracterizados.

\section{Factores genéticos}

La EC presenta un importante componente genético, reflejado en varios casos por familia y concordancia entre gemelos homocigotos de alrededor de $70 \%$ a $75 \% 17$. Esta enfermedad se hereda de manera poligénica con participación de genes HLA y no HLA. Los genes HLA contribuyen mayoritariamente representando, al menos, la mitad de la predisposición genética. Los genes HLA, DQ-2 (presente en 80\%-95\% de los pacientes) y DQ-8 son necesarios para el desarrollo de esta enfermedad. La ausencia de genes DQ-2 o DQ-8 predice negativamente el desarrollo de EC, lo cual es de utilidad para descartar su diagnóstico. Sin embargo, muchos pacientes que portan estos alelos no desarrollan EC, por lo que su presencia es necesaria pero no suficiente para el desarrollo de la enfermedad ${ }^{18}$. Por otra parte, individuos que son homocigotos para estos genes HLA presentan, al menos, 5 veces mayor riesgo de desarrollar la enfermedad, que los heterocigotos $^{19}$. En Chile, un estudio genético de 62 pacientes celíacos y 126 familiares demostró una mayor frecuencia del alelo DQA1*0501 (48\%), y predominancia de combinaciones DQ-8 para ambos grupos $^{10}$. Las moléculas HLA DQ-2 y DQ-8 se unen característicamente a aminoácidos hidrofóbicos, con péptidos de carga negativa con ubicación específica $^{20}$.

Genes no HLA participan en la susceptibilidad a la enfermedad, pero su influencia no está aclarada. Durante la última década, se ha realizado una búsqueda intensiva de genes asociados a la EC. Las regiones donde se ubican esos genes estarían en los cromosomas 15 y 1921,22. Aunque diversos polimorfismos han sido vinculados al desarrollo de la EC, aún no se ha podido establecer una clara participación de estas variantes en la patogénesis de la enfermedad. Por ejemplo, los polimorfismos en el gen del inhibidor de la serino peptidasa, clase E (SERPINE 2), estarían asociados con la enfermedad, encontrándose menor expresión de éste en biopsias de pacientes celíacos. SERPINE 2 tiene importancia en la producción de la matriz extracelular23. Se describió, además, la asociación a un polimorfismo cercano a los genes de IL-2 e IL-21 24 . Por último, fue demostrado que un polimorfismo de IL-23R podría ser locus de susceptibilidad para la $\mathrm{EC}^{25}$.

La EC se asocia a diferentes patologías de origen autoinmune, como la diabetes mellitus tipo 1 y la dermatitis herpetiforme entre otras, lo cual puede atribuirse a la existencia común de genes predisponentes.

\section{Factores ambientales}

Dieta. El gluten, presente en el trigo, es utilizado como genérico para referirse a las proteínas desencadenantes de la enfermedad. Sin embargo, otras proteínas, como las hordeínas y las secalinas presentes en la cebada y el centeno, respectivamente, también son ricas en glutamina y prolina, lo cual determina una difícil digestión en el tracto digestivo superior, debido a la ausencia de enzimas con actividad prolil-endopeptidasa. La digestión incompleta de estas proteínas, conduce a la acumulación de péptidos grandes, de hasta 50 aminoácidos, en el intestino delgado ${ }^{26}$. Entre 
éstos, destaca la gliadina, integrante de la fracción alcohol soluble del gluten, y sus isoformas $\gamma$ y $\alpha$ se consideran causantes de la patogenia de esta enfermedad ${ }^{18}$.

El péptido 33-mer de la $\alpha$-gliadina, el segmento más tóxico de esta proteína, es sustrato para la tTG que se expresa en la lámina propia ${ }^{27}$. La tTG es una enzima implicada en la reparación del tejido dañado. Su activación es tiol-ester dependiente y ante una reducción en los niveles de zinc, en situaciones de estrés, inflamación o infección, la enzima se activa. La tTG se une con gran avidez y especificidad a la gliadina deamidando residuos de glutamina a glutamato. Este último presenta carga negativa, lo que favorece su unión a HLA DQ-2 y DQ-827. Todo lo anterior permite que la gliadina sea presentada como antígeno, desencadenando la respuesta inmune en los pacientes con EC.

La lactancia prolongada ${ }^{28}$ y la introducción tardía del gluten durante los primeros años de vida, se asocia a una menor prevalencia de EC, lo cual podría deberse a un comienzo más tardío de la enfermedad ${ }^{29}$.

Permeabilidad intestinal. En condiciones fisiológicas, el epitelio intestinal es impermeable a macromoléculas luminales, como el gluten. En pacientes con EC la permeabilidad epitelial aumenta, facilitando el paso de la gliadina a la lámina propia. Esta característica no es atribuible al daño epitelial por la respuesta inflamatoria, ya que también se ha demostrado una mayor permeabilidad epitelial previa al desarrollo de la EC y en familiares no enfermos. La permeabilidad intestinal puede verse aumentada por diversos factores, como la acción de citoquinas proinflamatorias (TNF- $\alpha$, IL-17 e IFN- $\gamma$ ), la interacción bacteriana con los enterocitos, la migración de células inflamatorias a través del epitelio, la activación de transportadores de nutrientes, agentes tóxicos externos, o no tener una causa aparente. La mayor permeabilidad intestinal, presente en esta enfermedad, se explicaría por defectos de las uniones estrechas, lo cual persiste posdieta sin gluten. Alteraciones en la miosina IXB (MYO9B) ${ }^{30}$, o una disminución de la zonulina ${ }^{31}$, proteínas integrante y estabilizadora de las uniones estrechas respectivamente, han sido identificadas en la EC. Tanto en las enfermedades inflamatorias intestinales como en la EC se produce un defecto en la barrera epitelial, previo al desarrollo de la enfermedad, lo cual sugiere un evento fisiopatológico compartido. En la búsqueda de defectos genéticos comunes para ambas patologías, se identificó una asociación con mutaciones puntuales en Par-3 partitioning defective 3 (PARD3) y quinasa 2 guanilada asociada a membrana (MAGI2) tanto en EC como colitis ulcerosa, sugiriendo una predisposición genética común relacionada a defectos en los integrantes de las uniones estrechas ${ }^{32}$.

Infecciones. El riesgo de desarrollar EC aumenta en relación al número de infecciones gastrointestinales antes de los 6 meses de edad ${ }^{33}$, y en los niños nacidos en verano ${ }^{34}$. La inflamación e infecciones a nivel intestinal pueden aumentar la permeabilidad intestinal y aumentar la secreción de tTG intracelular. Las infecciones frecuentes por rotavirus producen mayor riesgo de desarrollar EC en individuos con predisposición genética conocida ${ }^{35}$.

Además, las infecciones por adenovirus tendrían un papel central en el desarrollo de la enfermedad. La proteína EIB del adenovirus presenta una estructura similar a la $\alpha$-gliadina. Sin embargo, anticuerpos específicos contra esta proteína EIB no han sido identificados en los pacientes celíacos, ni tampoco reactividad cruzada entre LT específicos para gliadina con la proteína viral $^{36}$.

Por otra parte, la secreción de IFN- $\alpha$ durante las infecciones virales y bacterianas intracelulares tendría un impacto en la pérdida de la tolerancia inmunológica local. Los IFN de tipo I ( $\alpha$ y $\beta$ ) promueven la diferenciación y mantención de la respuesta inmune celular con un perfil $\mathrm{Th}^{37}$. Además la secreción de IFN- $\alpha$ estimula la secreción de IFN- $\gamma$ e IL-15, que participan en la patogenia de esta enfermedad ${ }^{38}$. Reafirmando lo anterior se han descrito casos de desarrollo de EC durante el tratamiento con IFN- $\alpha$ para la infección por virus hepatitis $\mathrm{C}^{39}$.

Flora comensal. Un desbalance en la flora comensal podría contribuir en la patogenia de la EC. La microflora de pacientes celíacos y sus familiares de primer grado se encuentra alterada respecto a la población control ${ }^{40}$. Estudios han demostrado una menor cantidad de Lactobacilo y Bifidobacte- 
rium en pacientes celíacos activos e inactivos, respecto a controles. Por otro lado, la concentración de bacterias Gram (-), en especial E coli y Bacteroides, es mayor en pacientes con enfermedad activa, en relación a inactivos y controles ${ }^{41}$.

\section{Factores inmunológicos}

Inmunología del intestino. La mucosa intestinal, cuenta con un complejo sistema inmune (GALT, gut associated lymphoid tissue). El continuo estímulo antigénico activa la inmunidad de mucosas que constantemente debe discriminar entre antígenos patógenos y de la dieta. Las placas de Peyer (PP), lámina propia y los ganglios mesentéricos, forman parte del GALTs, donde se localizan las células dendríticas (CDs). El material antigénico proveniente de células epiteliales, alimentos o bacterias comensales puede presentarse por las CDs a células T presentes en los GALTs. En un ambiente no inflamatorio se induce un estado de inactivación del linfocito, generando tolerancia inmunológica.
La respuesta inmune innata del intestino está mediada fundamentalmente por tres tipos célulares: células de Paneth (CP), epiteliales diferenciadas tipo $\mathrm{M}$ y CDs. Cada tipo celular ejerce un papel específico en la defensa contra patógenos. Las CDs conectan la inmunidad innata con la adaptativa, a través de la activación de linfocitos $\mathrm{T}$ naïve presentes en el GALTs. Este proceso permite dirigir la respuesta inmune hacia un perfil Th1, Th2 o Th17, dependiendo del patógeno y el ambiente de citoquinas circundantes (Figura 1).

Los linfocitos intraepiteliales (LEs) se localizan entre los enterocitos y se encuentran en contacto con el lumen intestinal y la lámina propia. Los LEs son las primeras células inmunocompetentes en detectar antígenos de la vía oral, y presumiblemente discernir entre antígenos inocuos de patógenos. La función específica de los LIEs es aún controversial, pero es claro que participan activamente en la respuesta inmunológica innata intestinal. En el intestino delgado se han descrito tres poblaciones de LIEs, dependiendo del tipo de

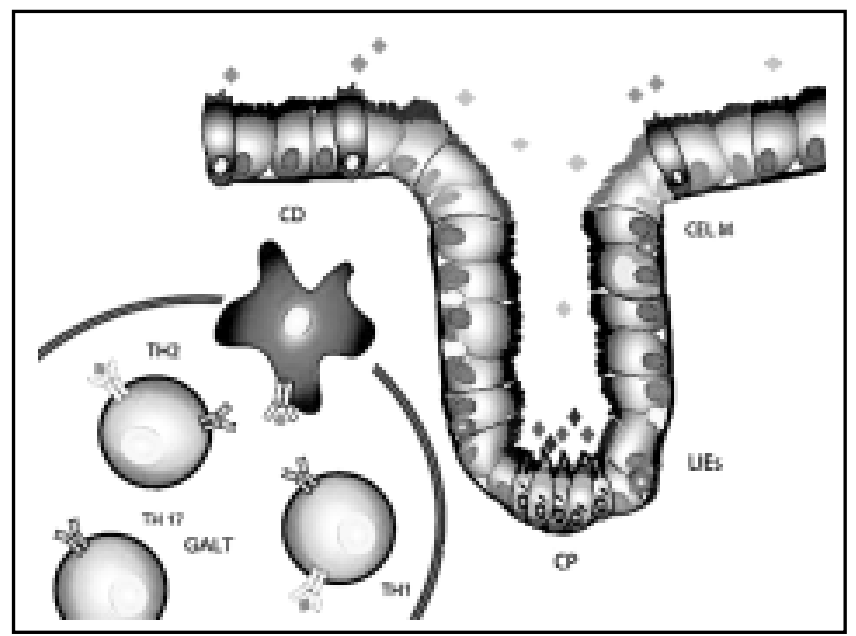

Figura 1. Inmunidad intestinal. La respuesta inmune innata del intestino está mediada fundamentalmente por tres tipos de células: CP, localizadas en la base de las criptas de Lieberkühn, epiteliales diferenciadas de tipo M, distribuidas a lo largo del tracto digestivo, y las CDs. Estas últimas conectan la inmunidad innata con la adaptativa. Este proceso permite dirigir la respuesta inmune hacia un perfil Th1, Th2 o Th17, dependiendo del tipo de patógeno y el ambiente de citoquinas circundante.

Los LEs se localizan entre los enterocitos y se encuentran en contacto con el lumen intestinal y la lámina propia en el intestino humano. Son las primeras células inmunocompetentes en reconocer antígenos luminales, y discriminar entre antígenos inocuos y patógenos. Su función específica es aún controversial, aunque participan activamente en la respuesta inmune innata intestinal. 
receptor de célula T (TcR): $\alpha ß$ CD8+CD4-, $\gamma \delta$ CD8CD4- y $\alpha ß$ CD8-CD4+.

Alteraciones en la respuesta inmune innata y adquirida celular estarían involucradas en la patogenia de la $\mathrm{EC}^{42}$.

Inmunidad innata. La respuesta inmune inflamatoria a la $\alpha$-gliadina induce la expresión de citoquinas proinflamatorias, tales como la IL-1, el TNF- $\alpha$ y la IL-8, principalmente en las etapas tempranas de la $\mathrm{EC}^{43}$.

Las subpoblaciones de LEs en pacientes celíacos se alteran, observándose un aumento de la subpoblación TcR- $\alpha ß / C D 8+/ C D 4-$, la cual disminuye al comenzar la dieta sin gluten. Por otra parte, la subpoblación de TcR- $\gamma \delta$ CD8+/CD4aumenta tanto en pacientes en dieta como en no tratados ${ }^{44}$, postulándose que estos linfocitos tendrían un importante papel en la patogenia de la $\mathrm{EC}^{42,45}$

Como parte de la subpoblación TcR- $\alpha ß /$ CD8+/CD4- aumentada en EC, existe un subgru- po que expresa receptores de NK (NKG2D, NKp44 y NKp46) que median la destrucción de enterocitos en la EC activa. Estos reconocen señales de estrés, como MIC A y B (cadena asociada a MHC clase I A y B) y HLA-E (antígeno leucocitario humano-E) que sólo se expresan en enterocitos dañados, lo que explicaría la participación de algunos LIEs en la destrucción epitelial, mediante secreción de IFN- $\gamma$, perforina $\mathrm{y}$ granzima $\mathrm{B}^{46,47}$. Estos LIEs serían los efectores de la respuesta inmune innata (Figura 2).

La IL-15 tiene un papel central en este proceso patogénico. El péptido 31-43 derivado de la $\alpha$ gliadina estimula la secreción de IL-15 por las células epiteliales y CDs presentes en la lámina propia, lo cual, podría contribuir a la alteración de la población de LIEs CD8+a $\aleph^{48}$. La IL-15 además, induce la expresión de los receptores de NK en los LIEs, como también MIC y HLA-E, que son blanco de las células citotóxicas ${ }^{38,49}$.

Por otra parte, la expansión clonal de LIEs aberrantes, se asocia a la EC refractaria y el

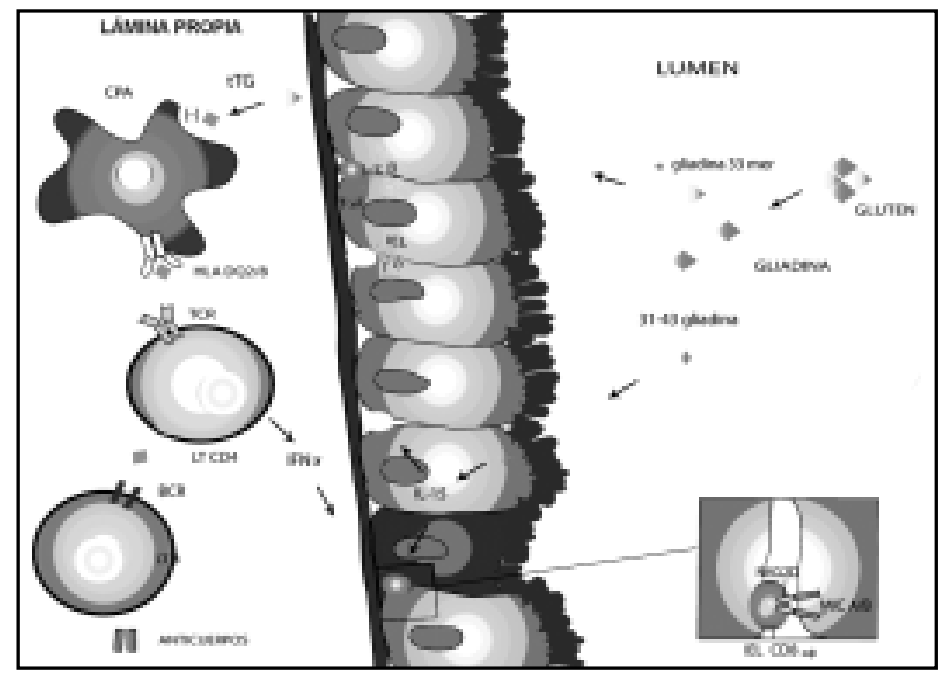

Figura 2. Patogenia de la EC. El gluten presente en el lumen intestinal se metaboliza a gliadina. En su forma 33mer, la $\alpha$-gliadina atraviesa la barrera epitelial, con una permeabilidad aumentada, alcanzando la lámina propia. A este nivel es deamidada por la tTG, lo cual permite que su reconocimiento por los HLA DQ-2 o DQ8. La CD presenta la gliadina metabolizada al LT CD4, el que secreta citoquinas proinflamatorias, las cuales producen daño en los enterocitos. Además activa a linfocitos B los cuales producen anticuerpos contra esta proteína. El fragmento 31-43 de la gliadina, induce producción de IL15 por el enterocito, la cual estimula la proliferación de LIEs. El subgrupo CD8/ $\alpha$ promueve la expresión de NKG2D, que reconoce a sus ligandos MICA y MICB, desencadenando la actividad citotóxica sobre el enterocito, mientras el subgrupo $\gamma \delta$ parece tener un rol inmunorregulador. 
desarrollo de linfoma ${ }^{50}$. La expansión de los LIEs, se debería a la sobrexpresión de IL-15 por el epitelio intestinal ${ }^{38}$, es por eso, que el desarrollo de un antagonista de la IL-15 representa una posible estrategia terapéutica de la $\mathrm{EC}^{50}$.

Los LEs- $\gamma \delta$ corresponden a una subpoblación linfocitaria inmunorreguladora, y son posibles mediadores de la tolerancia oral a antígenos de la dieta en pacientes sanos ${ }^{51}$. En la mucosa intestinal, estas células tienen un papel de vital importancia en la mantención de la integridad epitelial y su reparación, a través de la producción de citoquinas y factores de crecimiento ${ }^{52}$. Ratones deficientes en la subunidad d del TcR, que no cuentan con LEs $\gamma \delta$, muestran un daño de la mucosa exagerado ante infecciones parasitarias ${ }^{53}$. Además, esta subpoblación linfocitaria expresa el mARN de TGF-ß e IL-10 e inhiben la actividad citotóxica de células $\mathrm{T}$ invitro ${ }^{54}$. Los pacientes celíacos que presentan un mayor número de células $\gamma \delta$, presentan una menor inflamación y sintomatología, hallazgo que refuerza su posible papel supresor ${ }^{55}$.

Linfocitos TcR- $\gamma \delta / C D 8+$ expresan NKG2A (receptor inhibidor de células NK) y TGF-ß1 (factor de crecimiento tumoral) intracelular. Estos linfocitos están aumentados en pacientes celíacos en dieta respecto a celíacos activos sin tratamiento. El cultivo de estos linfocitos con células TcR- $\alpha ß /$ CD8+, estimuladas con IL-15, en presencia de enterocitos HLA-E (+), produce un menor porcentaje de CD8 citotóxicos, que expresan IFN- $\gamma$, granzima-B y NKG2D. Esta inhibición de la actividad citotóxica se pierde parcialmente bloqueando TGF-ß o NKG2A y HLA-E, lo cual demuestra que la supresión es mediada al menos parcialmente por la secreción de TGF-ß, como resultado de la unión de NKG2A a HLA-E. Lo anterior, reafirma que estos LEs pueden tener una función inmunorreguladora en la $\mathrm{EC}^{56}$.

\section{REFERENCIAS}

1. Shan L, Molberg O, Parrot I, Hausch F, Filiz F, Gray GM ET AL. Structural basis for gluten intolerance in celiac sprue. Science 2002; 297: 2275-9.

2. Shewry PR, Halford NG. Cereal seed storage proteins: structures, properties and role in grain utilization. J Exp Bot 2002; 53: 947-58.
Inmunidad adaptativa. La respuesta inmune adaptativa está comandada por los LT CD4+, presentes en la lámina propia, que reconocen la $\alpha$-gliadina presentada por CDs en contexto de heterodímeros HLA DQ-2 o DQ-8, los que se encargan de producir el daño de la mucosa (Figura 2). Los subtipos de HLA DQ-2 o DQ-8, se expresan pobremente en mucosa normal, aunque pueden ser inducidos en CDs activadas por IFNs durante cuadros inflamatorios infecciosos ${ }^{42}$. La $\alpha$ gliadina induce la maduración de las CDs, lo que les permite presentarla a los $\mathrm{LT}^{57}$. Péptidos del gluten con distintas propiedades inmunogénicas estimulan a los LT, sin embargo, una vez que se inicia la respuesta $\mathrm{T}$ específica, ocurre una amplia respuesta al gluten, encontrándose células $\mathrm{T}$ especificas para varios péptidos distintos ${ }^{36}$. La activación de estos linfocitos $\mathrm{T}$ específicos induce la liberación de IFN- $\gamma$ favoreciendo la polarización hacia una respuesta Th1 ${ }^{58}$. Los linfocitos CD4+ además activan a los linfocitos $\mathrm{B}$, los cuales producen anticuerpos antigliadina, antiendomisio y antitransglutaminasa ${ }^{18}$. Este último anticuerpo, está dirigido contra la tTG, sin embargo no afecta su función ${ }^{9}$.

La cascada inflamatoria promueve la liberación de metaloproteinasas y otros mediadores de daño tisular, induciendo hiperplasia de las criptas y daño de las vellosidades intestinales.

Queda claro que varios factores genéticos, ambientales e inmunológicos, determinan el desarrollo de la EC en mayor o menor grado de importancia. Dentro de este último mecanismo, desequilibrios tanto en la inmunidad adquirida como la innata juegan un importante rol. Es por ello la relevancia de investigaciones futuras que permitan determinar cuáles de estos factores inmunológicos son susceptibles de ser intervenidos en la búsqueda de nuevas estrategias terapéuticas para los pacientes con EC.

3. REWERS M. Epidemiology of celiac disease: what are the prevalence, incidence, and progression of celiac disease? Gastroenterology 2005; 128: S47-51.

4. Gasbarrini G, Malandrino N, Giorgio V, Fundaro C, Cammarota G, Merra G et al. Celiac disease: what's new about It? Dig Dis 2008; 26: 121-7.

5. Gómez JC, Selvaggio GS, Viola M, Pizarro B, La Motta G, De Barrio S et al. Prevalence of celiac 
disease in Argentina: screening of an adult population in the La Plata area. Am J Gastroenterol 2001; 96: 2700-4.

6. Gandolfi L, Pratesi R, Córdoba JC, Tauil PL, Gasparin $\mathrm{M}$, CATASSI C. Prevalence of celiac disease among blood donors in Brazil. Am J Gastroenterol 2000; 95: 689-92.

7. Lohi S, Mustalahti K, Kaukinen K, Laurila K, Cown P, RISSANEN H ET AL. Increasing prevalence of coeliac disease over time. Aliment Pharmacol Ther 2007; 26: 1217-25.

8. Catassi C, Fabiani E, Ratsch im, Coppa GV, Giorgi PL, Pierdomenico R ET aL. The coeliac iceberg in Italy. A multicentre antigliadin antibodies screening for coeliac disease in school-age subjects. Acta Paediatr Suppl 1996; 412: 29-35.

9. Barton SH, Murray JA. Celiac disease and autoimmunity in the gut and elsewhere. Gastroenterol Clin North Am 2008; 37: 411-28.

10. Araya M, Mondragón A, Pérez-Bravo F, Roessier JL, Alarcón T, Ríos G et al. Celiac disease in a Chilean population carrying Amerindian traits. J Pediatr Gastroenterol Nutr 2000; 31: 381-6.

11. Sardy M, Karpati S, Merkl B, Paulsson M, Smyth N. Epidermal transglutaminase (TGase 3) is the autoantigen of dermatitis herpetiformis. J Exp Med 2002; 195: 747-57.

12. Maki M, Mustalahti K, Kokkonen J, Kulmala P, Haapalahti M, Karttunen $T$ et al. Prevalence of Celiac disease among children in Finland. N Engl J Med 2003; 348: 2517-24.

13. MacDonald TT, Bajaj-Eшiott M, Pender SL. T cells orchestrate intestinal mucosal shape and integrity. Immunol Today 1999; 20: 505-10.

14. GreEn PH, Jabri B. Coeliac disease. Lancet 2003; 362: 383-91.

15. Heredia PC, CASTro PF, Palma HJ. [Adult celiac disease]. Rev Méd Chile 2007; 135: 1186-94.

16. Cataldo F, Marino V, Ventura A, Bottaro G, Corazza GR. Prevalence and clinical features of selective immunoglobulin A deficiency in coeliac disease: an Italian multicentre study. Italian Society of Paediatric Gastroenterology and Hepatology (SIGEP) and «Club del Tenue»Working Groups on Coeliac Disease. Gut 1998; 42: 362-5.

17. Greco L, Romino R, Coto I, Di Cosmo N, Percopo S, MagLO M ET AL. The first large population based twin study of coeliac disease. Gut 2002; 50: 624-8.

18. Green PH, Cewer C. Celiac disease. N Engl J Med 2007; 357: 1731-43.

19. Mearin ML, Biemond I, Pena AS, Polanco I, Vázquez C, SCHREUdER GT et al. HLA-DR phenotypes in Spanish coeliac children: their contribution to the understanding of the genetics of the disease. Gut 1983; 24: 532-7.

20. Stepniak D, Vader LW, Kooy Y, Van Veeien PA, MoustaKas A, PAPANDREou NA et al. T-cell recognition of HLA-DQ2-bound gluten peptides can be influenced by an N-terminal proline at $\mathrm{p}-1$. Immunogenetics 2005; 57: 8-15.

21. Babron MC, Nilsson S, Adamovic S, Naluai AT, Wahlstrom J, Ascher H et al. Meta and pooled analysis of European coeliac disease data. Eur J Hum Genet 2003; 11: 828-34.

22. Van Beizen MJ, Meijer JW, Sandkujul LA, Bardoel AF, Mulder CJ, Pearson PL et al. A major non-HLA locus in celiac disease maps to chromosome 19. Gastroenterology 2003; 125: 1032-41.

23. Castellanos-Rubio A, Martin-Pagola A, Santin I, Hualde I, Aransay aM, Castano L et al. Combined functional and positional gene information for the identification of susceptibility variants in celiac disease. Gastroenterology 2008; 134: $738-46$.

24. Van Heel DA, Franke L, Hunt KA, Gwiшam R, Zhernakova A, InOUYe M et al. A genome-wide association study for celiac disease identifies risk variants in the region harboring IL2 and IL21. Nat Genet 2007; 39: 827-9.

25. Nunez C, Dema B, Cenit MC, Polanco I, Maluenda C, ARROYo R ET AL. IL23R: a susceptibility locus for celiac disease and multiple sclerosis? Genes Immun 2008; 9: 289-93.

26. Shan L, Qiao SW, Arentz-Hansen H, Molberg O, Gray GM, SOWD LM ET AL. Identification and analysis of multivalent proteolytically resistant peptides from gluten: implications for celiac sprue. J Proteome Res 2005; 4: 1732-41.

27. Stenberg P, Roth EB, Sjoberg K. Transglutaminase and the pathogenesis of coeliac disease. Eur J Intern Med 2008; 19: 83-91.

28. Ivarsson A, Hernell O, Stenlund H, Persson LA. Breastfeeding protects against celiac disease. Am J Clin Nutr 2002; 75: 914-21.

29. Norris JM, Barriga K, Hoffenderg EJ, Taki I, Miao D, HAAS JE ET AL. Risk of celiac disease autoimmunity and timing of gluten introduction in the diet of infants at increased risk of disease. JAMA 2005; 293: 2343-51.

30. Wolters VM, Verbeek WH, Zhernakova A, OnlandMoret C, Schreurs MW, Monsuur AJ et al. The MYO9B gene is a strong risk factor for developing refractory celiac disease. Clin Gastroenterol Hepatol 2007; 5: 1399-405, 1405 e1-2. 
31. Drago S, El Asmar R, Di Pierro M, Grazia Ciemente M, TRIPATHI A ET AL. Gliadin, zonulin and gut permeability: Effects on celiac and non-celiac intestinal mucosa and intestinal cell lines. Scand J Gastroenterol 2006; 41: 408-19.

32. Wapenaar MC, Monsuur A, Van Bodegraven A, Weersma RK, Bevova M, LinsKens R ET al. Associations With Tight Junction Genes Pard3 And Magi2 In Dutch Patients Point To A Common Barrier Defect For Celiac Disease And Ulcerative Colitis. Gut 2007; 57: 463-7.

33. Ivarsson A. The Swedish epidemic of coeliac disease explored using an epidemiological approach-some lessons to be learnt. Best Pract Res Clin Gastroenterol 2005; 19: 425-40.

34. Ivarsson A, Hernell O, Nystrom L, Persson La. Children born in the summer have increased risk for coeliac disease. J Epidemiol Community Health 2003; 57: 36-9.

35. Pavone P, Nicolni E, Taibi R, Ruggieri M. Rotavirus and celiac disease. Am J Gastroenterol 2007; 102: 1831.

36. StepnIAK D, Koning F. Celiac disease-sandwiched between innate and adaptive immunity. Hum Immunol 2006; 67: 460-8.

37. Brinkmann V, Geiger T, Alkan S, Heusser CH. Interferon alpha increases the frequency of interferon gamma-producing human CD4+ T cells. J Exp Med 1993; 178: 1655-63.

38. Mention JJ, Ben Ahmed M, Begue B, Barbe U, Verkarre V, ASNAFI V ET AL. Interleukin 15: a key to disrupted intraepithelial lymphocyte homeostasis and lymphomagenesis in celiac disease. Gastroenterology 2003; 125: 730-45.

39. Cammarota G, Cuoco L, Cianci R, Pandolfi F, GasbarriNI G. Onset of coeliac disease during treatment with interferon for chronic hepatitis C. Lancet 2000; 356: 1494-5.

40. Tjelistrom B, Stenhammar L, Hogberg L, Falth-Magnusson K, Magnusson KE, Midtvedt T et al. Gut microflora associated characteristics in first-degree relatives of children with celiac disease. Scand J Gastroenterol 2007; 42: 1204-8.

41. Nadal I, Donant E, Ribes-Koninckx C, Calabuig M, Sanz $Y$. Imbalance in the composition of the duodenal microbiota of children with coeliac disease. J Med Microbiol 2007; 56: 1669-74.

42. Kagnoff MF. Celiac disease: pathogenesis of a model immunogenetic disease. J Clin Invest 2007; 117: 41-9.

43. Chernavsky aC, Páez MC, Periolo N, Correa P, Guilen L, NIVELONI SI ET AL. The simultaneous presence of IL-
1B and TNFA two-positions risk haplotypes enhances the susceptibility for celiac disease. Cytokine 2008; 42: 48-54.

44. Kutlu T, Brousse N, Rambaud C, Le Deist F, Schittz J, Cerf-Bensussan N. Numbers of T cell receptor (TCR) alpha beta+ but not of TcR gamma delta+ intraepithelial lymphocytes correlate with the grade of villous atrophy in coeliac patients on a long term normal diet. Gut 1993; 34: 208-14.

45. BRANDTZAEg P. The changing immunological paradigm in coeliac disease. Immunol Lett 2006; 105: 127-39.

46. Meresse B, Chen Z, Ciszewski C, Tretiakova M, Bhagat G, KRAUSZ TN ET AL. Coordinated induction by IL15 of a TCR-independent NKG2D signaling pathway converts CTL into lymphokine-activated killer cells in celiac disease. Immunity 2004; 21: 357-66.

47. Meresse B, Curran SA, Ciszewski C, Orbeiyan G, Setty M, Bhagat G et aL. Reprogramming of CTLs into natural killer-like cells in celiac disease. J Exp Med 2006; 203: 1343-55.

48. Maiuri L, Ciacci C, Ricciardewi I, Vacca L, Raia V, Auricchio S ET AL. Association between innate response to gliadin and activation of pathogenic $\mathrm{T}$ cells in coeliac disease. Lancet 2003; 362: 30-7.

49. Maiuri L, Ciacci C, Vacca L, Ricciardewi I, Auricchio S, Quaratino $S$ ET AL. IL-15 drives the specific migration of CD94+ and TCR-gammadelta+ intraepithelial lymphocytes in organ cultures of treated celiac patients. Am J Gastroenterol 2001; 96: 150-6.

50. Cemuer C, Dejabesse E, Helmer C, Patey N, MatuchansKY C, JABRI B ET AL. Refractory sprue, coeliac disease, and enteropathy-associated T-cell lymphoma. French Coeliac Disease Study Group. Lancet 2000; 356: 203-8.

51. FuJihashi $K$, Taguchi $T$, Aicher WK, McGhee JR, Bluestone JA, ELdRIDGe JH et al. Immunoregulatory functions for murine intraepithelial lymphocytes: gamma/delta T cell receptor-positive (TCR+) T cells abrogate oral tolerance, while alpha/beta TCR+ T cells provide B cell help. J Exp Med 1992; 175: 695707.

52. BoIsMenu R. Function of intestinal gammadelta $\mathrm{T}$ cells. Immunol Res 2000; 21: 123-7.

53. Roberts SJ, Smith AL, West AB, Wen L, Findiy RC, OWEN MJ ET AL. T-cell alpha beta + and gamma delta + deficient mice display abnormal but distinct phenotypes toward a natural, widespread infection of the intestinal epithelium. Proc Natl Acad Sci USA 1996; 93: 11774-9.

54. KaPP JA, KaPP LM, McKenNa KC, LaKE JP. Gammadelta T-cell clones from intestinal intraepithelial lympho- 
cytes inhibit development of CTL responses ex vivo. Immunology 2004; 111: 155-64.

55. Hayday A, Theodoridis E, Ramsburg E, Shires J. Intraepithelial lymphocytes: exploring the Third Way in immunology. Nat Immunol 2001; 2: 997-1003.

56. Bhagat G, Naiyer AJ, Shah JG, Harper J, Jabri B, Wang TC ET AL. Small intestinal CD8+TCR gammadelta+NKG2A+ intraepithelial lymphocytes have attributes of regulatory cells in patients with celiac disease. J Clin Invest 2008; 118: 281-93.

57. Palova-Jelinkova L, Rozkova D, Pecharova B, Bartova J, Sediva A, Tlaskalova-Hogenova H et al. Gliadin fragments induce phenotypic and functional maturation of human dendritic cells. J Immunol 2005; 175: 7038-45.

58. Nilsen EM, Jahnsen FL, Lundin KE, Johansen FE, FAusa O, SOLD LM ET AL. Gluten induces an intestinal cytokine response strongly dominated by interferon gamma in patients with celiac disease. Gastroenterology 1998; 115: 551-63.

59. Tikkakoski S, Savilahti E, KolHo KL. Undiagnosed coeliac disease and nutritional deficiencies in adults screened in primary health care. Scand J Gastroenterol 2007; 42: 60-5. 